\title{
MEASUREMENT AND ANALYSIS OF THERMAL PARAMETERS AND EFFICIENCY OF LASER HETEROSTRUCTURES AND LIGHT-EMITTING DIODES
}

\author{
Yurii A. Bumai $^{1)}$, Aleh S. Vaskou ${ }^{1)}$, Valerii K. Kononenko ${ }^{2)}$ \\ 1) Belarusian National Technical University, Independence Ave., 65,220013 Minsk, Belarus (bumai@tut.by,o_vascov@mail.ru) \\ 2) Stepanov Institute of Physics NASB, Independence Ave., 70, 220072 Minsk, Belarus ( $\$ lavik@dragon.bas-net.by, + 375 17 284 0435 )
}

\begin{abstract}
A thermal resistance characterization of semiconductor quantum-well heterolasers in the AlGaInAs-AlGaAs system $\left(\lambda_{\mathrm{st}} \approx 0.8 \mu \mathrm{m}\right)$, GaSb-based laser diodes $\left(\lambda_{\mathrm{st}} \approx 2 \mu \mathrm{m}\right)$, and power GaN light-emitting diodes (visible spectral region) was performed. The characterization consists in investigations of transient electrical processes in the diode sources under heating by direct current. The time dependence of the heating temperature of the active region of a source $\Delta T(t)$, calculated from direct bias change, is analyzed using a thermal $R_{T} C_{T}$ equivalent circuit (the Foster and Cauer models), where $R_{T}$ is the thermal resistance and $C_{T}$ is the heat capacity of the source elements and external heat sink. By the developed method, thermal resistances of internal elements of the heterolasers and light-emitting diodes are determined. The dominant contribution of a die attach layer to the internal thermal resistance of both heterolaser sources and light-emitting diodes is observed. Based on the performed thermal characterization, the dependence of the optical power efficiency on current for the laser diodes is determined.
\end{abstract}

Keywords: heterostructure, light-emitting diode, thermal resistance, efficiency.

() 2010 Polish Academy of Sciences. All rights reserved

\section{Introduction}

Heterostructure lasers and nowadays light-emitting diodes (LEDs) are widely applied in the photonic industry and particularly in metrology. To assure the required semiconductor source lifetime, quantum efficiency, power and emission spectrum, the diode junction temperature must be controlled [1,2]. Thermal resistance of the sources characterizes the effectiveness of heat transfer from the crystals to ambient. It is one of major factors determining the operation of radiative semiconductor devices [3]. The increased temperature of the diode active region results in accelerated degradation, deterioration of their characteristics and failures.

In the work, the structure of internal thermal resistance $R_{T}$ of power quantum-well (QW) heterostructure lasers in the AlGaInAs-AlGaAs system is determined. Such semiconductor radiators serve as pump sources of solid-state lasers and waveguide amplifiers [4, 5]. Thermal resistance characterization is also applied to QW heterostructure lasers in the GaInAsSbAlGaAsSb system, which emit at the wavelengths near $2 \mu \mathrm{m}$. Laser diodes of this spectral range are needed for high sensitivity gas analysis and environmental monitoring [6, 7]. Thermal parameters and the resistance structure of commercially available high-intensity $\mathrm{GaN}$ LEDs emitting visible light were also investigated. The determination of the thermal parameters gives a possibility to optimize the design of semiconductor sources. In addition, the obtained results are useful for generation of thermal models for SPICE simulation tasks and to study the efficiency, stability and package quality of diode sources. 


\section{Experimental}

Heterolasers in the AlGaInAs-AlGaAs system $\left(\lambda_{\mathrm{st}} \approx 0.8 \mu \mathrm{m}\right.$, output power up to $1 \mathrm{~W}$ in $\mathrm{CW}$ and to $2 \mathrm{~W}$ in pulsed regime), laser diodes in the GaInAsSb-AlGaAsSb system $\left(\lambda_{\mathrm{st}} \approx 2 \mu \mathrm{m}\right)$ and power GaN LEDs (Lumileds, $3 \mathrm{~W}$ ) were investigated. The active region of the AlGaInAs-AlGaAs heterolasers includes the AlGaInAs QWs (10 nm width) and the $\mathrm{Al}_{x} \mathrm{Ga}_{1-x} \mathrm{As}$ waveguide layers $(0.15 \mu \mathrm{m}$ width, $x=0.3 \div 0.6)$. The active region layers are nominally undoped. Spectral, threshold, and output power versus current characteristics and internal parameters of separate lasing elements and bars with similar structure were investigated in $[8,9]$. The active region of the GaInAsSb-AlGaAsSb heterolasers consists of three QWs (10 $\mathrm{nm}$ width) and a waveguide region $(0.8 \mu \mathrm{m}$ width).

The method of thermal characterization of diode sources is based on investigation of transient processes under self-heating by direct current $[10,11]$. The time dependence of the heating temperature of the device active region $\Delta T(t)$ (time resolution is of $2 \mu \mathrm{s}$ ) is calculated from the direct bias measured by an A/D converter (16-bit resolution) under a unit-step current pulse [12]. Temperature sensitive parameters of the investigated devices have been determined previously. In particular, changes in the forward voltage versus temperature provide values of the so-called K-factor of a diode source [13]. Note that the measurements at various pump currents of the heterolasers were carried out in time intervals corresponding to overheating of their active regions less than $20 \mathrm{~K}$. The $\Delta T(t)$ function contains the information on heat paths through various elements of a diode source, i.e., from the device crystal over the die attach layer to heat sink and ambient [12].

\section{Theoretical background}

The dependence $\Delta T(t)$ has been analyzed using (analogically to electric circuits) equivalent thermal ladder $R_{T} C_{T}$ circuits of the Foster and Cauer types, where $R_{T}$ corresponds to the thermal resistance and $C_{T}$ is the heat capacity of elements of the internal device structure and external heat sink. The mathematical form of $\Delta T(t)$ dependence is most simple for the Foster circuit presentation, i.e.:

$$
\Delta T(t)=P_{T} \sum_{i} R_{T i}\left(1-\exp \left(-\frac{t}{\tau_{i}}\right)\right) .
$$

Here $P_{T}$ is the power dissipated by the device, $R_{T i}$ is the thermal resistance of the $i$-th element, $\tau_{i}$ is the heat time constant for the $i$-th element of the source. The heat flux $P_{T}$ is related to the electric power $P$ according to the relation $P_{T}=(1-\eta) P$, where $\eta$ is the power efficiency of the diode source.

After derivation of (1) we construct a special function $R_{T}^{*}\left(\tau^{*}\right)$, i.e.:

$$
R_{T}^{*}\left(\tau^{*}\right)=\sum_{i} R_{T i} \frac{\tau^{*}}{\tau_{i}} \exp \left(1-\frac{\tau^{*}}{\tau_{i}}\right) .
$$

Using this formula and the measured $\Delta T(t)$ dependence, values of $R_{T i}$ and $\tau_{i}$ can be obtained [12]. The suggested method differs from the well-known formalism of the timeconstant spectrum determination $[14,15]$. The maxima of the function $R_{T}{ }^{*}\left(\tau^{*}\right)$ give the thermal resistance values for the device elements $R_{T i}$, as well as their positions $\tau^{*}$ on the time scale corresponding to the time constants $\tau_{i}=R_{T i} C_{T i}$ [12]. As far as the Foster circuit with heat capacities in series is an appropriate description, the real device construction can be recalculated to the more complex Cauer circuit (Fig. 1). Corresponding parameters $R_{T i}$ and $C_{T i}$ 
in the Foster-type circuits are transformed into the Cauer network thermal parameters $R_{T i}^{\prime}$ and $C_{T i}^{\prime}$, which have more physical behavior [16]. Modified thermal models are required to include a parallel heat and light transport [17].

a)

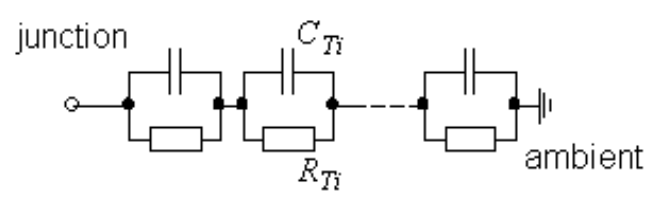

b)

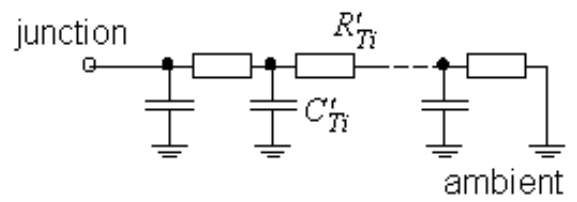

Fig. 1. Thermal equivalent circuits of a) Forster and b) Cauer types.

\section{Results and discussion}

As an example, the identified set of thermal resistance elements of the AlGaInAs-AlGaAs heterolaser 53-EZ-1 is shown in Fig. 2. In the function $R_{T}{ }^{*}\left(\tau^{*}\right)$, a dominant peak near $\tau^{*} \approx 1 \div 3 \mathrm{~ms}$ corresponding to the die attach layer is established. This peak corresponds mainly to the internal thermal resistance of the heterolaser (from laser crystal to copper plate). Significant scatter of thermal resistances $(1.3-5.0 \mathrm{~K} / \mathrm{W})$ of die attach layers for this type of lasers has been observed.

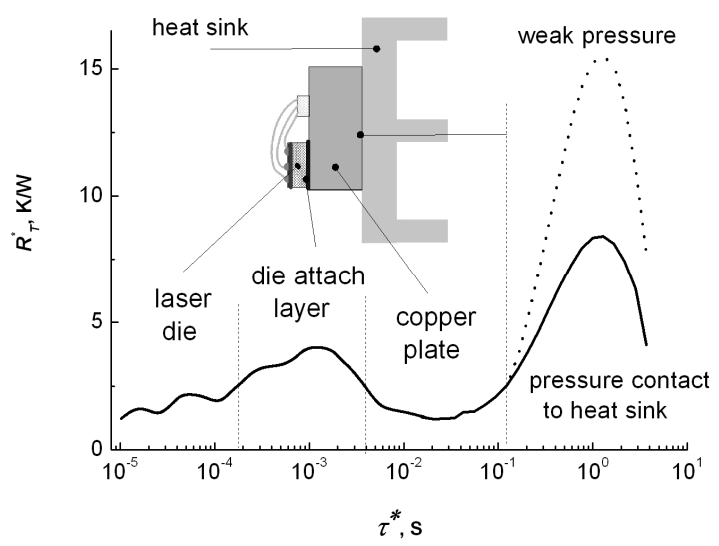

Fig. 2. Function $\left.R_{T}{ }^{*} \tau^{*}\right)$ and thermal resistance element identification for heterolaser 53-EZ-1.

Moreover, the dependence of optical output power efficiency $\eta$ of heterolasers on current $I$ can be determined from the analysis of heating temperature $\Delta T(t)$, using the assumption that the values of thermal resistances do not change with pump current. It follows that the laser power efficiency can be defined without optical measurements. The dependences of laser efficiencies versus pump current, obtained by this method, are shown in Fig. 3. As seen, the efficiency of the examined QW heterolasers at pump currents of 3 A reaches up to $\approx 40 \pm 5 \%$.

It is necessary to mention the quite good correlation between efficiencies of laser 204-ET2 , determined from thermal and optical measurements. The small difference can be explained by the fact that the integrated emission of the laser diode (both stimulated and spontaneous ones) is included in thermal measurements. The power efficiency of heterolasers is strongly dependent on pump current but changes slightly with the temperature rise of the laser active region $(\Delta T<20 \mathrm{~K})$ resulting from self-heating (Fig. 4). 
Degradation of heterolaser 35 -EZ-1 and a decrease of its efficiency down to $\approx 5 \%$ were observed during the measurements (Fig. 3). The output spectra of the degraded laser diode did not display stimulated emission radiation behavior and were similar to characteristics in the spontaneous emission regime. At the same time, the thermal resistance function as well as the current versus voltage (I-V) characteristic did not change. So, the most probable reason of the degradation is destruction of the facets of the Fabry-Pérot resonator.

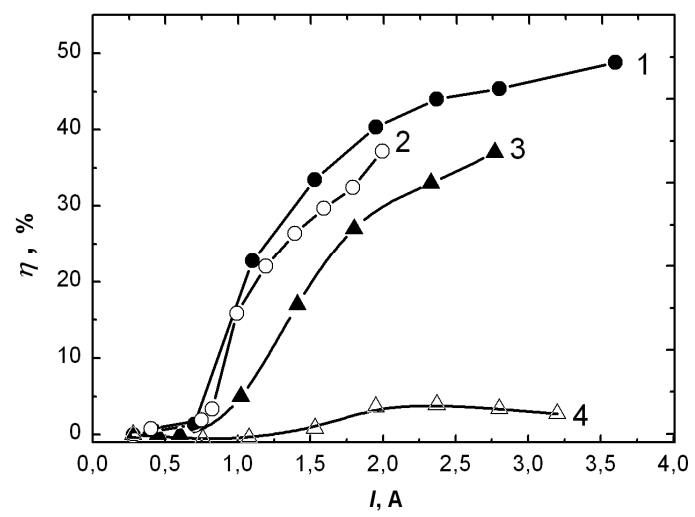

Fig. 3. Efficiency of heterolasers $(1,2)$ 204-ET-2 and $(3,4) 35$-EZ-1 versus current $\eta(I),(1,3$,$) thermal$ measurements, (2) optical data, (4) after degradation.

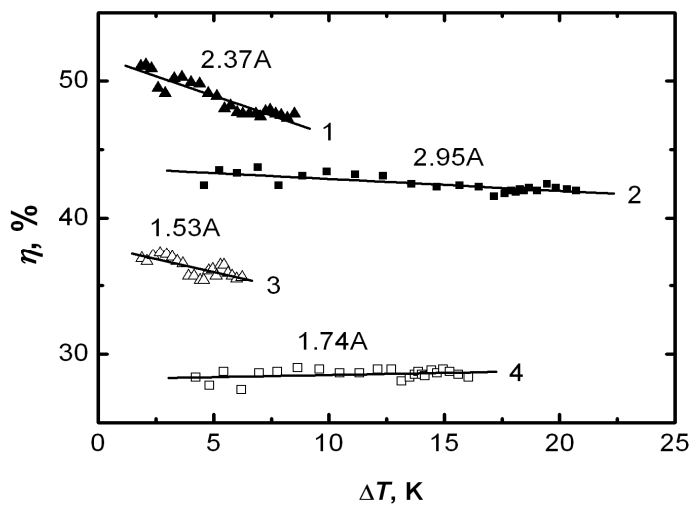

Fig. 4. Efficiencies of heterolasers $(1,3)$ 204-ET-2 and $(2,4) 35$-EZ-1 versus self-heating temperature rise $\eta(\Delta T)$ at different pump currents.

The thermal resistance functions of two GaInAsSb-AlGaAsSb heterolasers are shown in Fig. 5. The dominant peaks related to attachment of laser chips to copper plates as well as a large difference between the quality of attachment are clearly seen in the spectra. It should be noted that both GaSb-based lasers have large enough series resistances $(\approx 14 \Omega)$, as follows from pulsed I-V characteristics. 


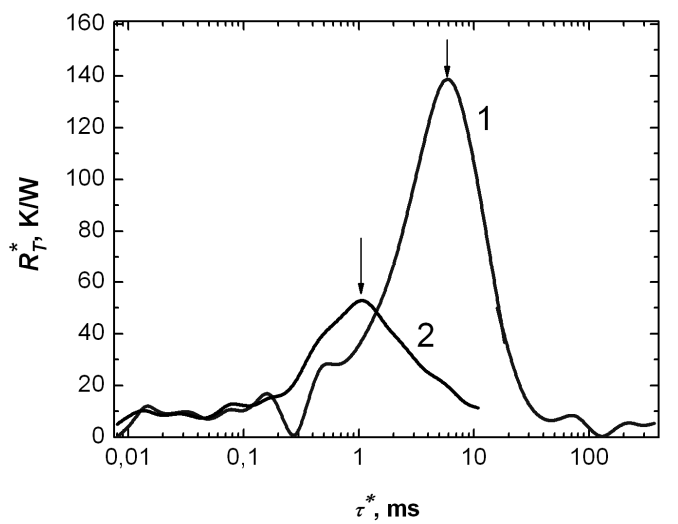

Fig. 5. Functions $R_{T}{ }^{*}\left(\tau^{*}\right)$ for two GaInAsSb-AlGaAsSb heterolasers, (1) $\lambda_{\mathrm{st}}=2.35 \mu \mathrm{m}$, (2) $\lambda_{\mathrm{st}}=2.12 \mu \mathrm{m}$.

The optical power efficiency versus pump current $\eta(I)$ for the long-wavelength GaInAsSbAlGaAsSb laser $\left(\lambda_{\mathrm{st}}=2.35 \mu \mathrm{m}\right)$ above the threshold $(\approx 25 \mathrm{~mA})$ is presented in Fig. 6 . Curve 1 , which demonstrates a low value of the laser efficiency $(<10 \%)$, can be explained by the large value of Joule heat generated by the series resistance of the laser. Curve 2 presents the same dependence when the heat losses in the series resistance are excluded from electric power. It indicates a possible high efficiency quantity (up to $37 \%$ ) that is close to the values for the AlGaInAs-AlGaAs QW heterolasers.

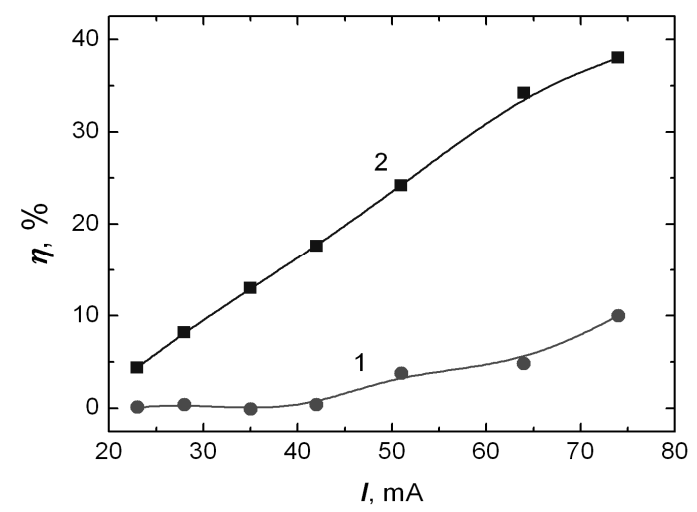

Fig. 6. Efficiency $\eta(I)$ of the heterolaser $\left(\lambda_{\mathrm{st}}=2.35 \mu \mathrm{m}\right)$ determined from thermal measurements (curves 1 and 2).

In addition, Fig. 7 shows the thermal resistance functions for two commercially available high-intensity GaN LEDs mounted on an aluminium metal core (MC) PCB plate and heat sink. The regions related to the die attach to a slug are clearly observed in the spectra. A large contribution of die attach layers into the internal thermal resistance of LEDs is similar to observation for heterolasers. As seen, for device LIIIP2JB (star) the use of a thermal interface material between the slug and MC PCB provides a low thermal resistance (curve 1). In Fig. 7 , is also illustrated a modification of the function $R_{T}{ }^{*}\left(\tau^{*}\right)$ (curve 2) for LED sample LXK2 (emitter) by a teflon film placed between the PCB plate and slug in order to test the method. 


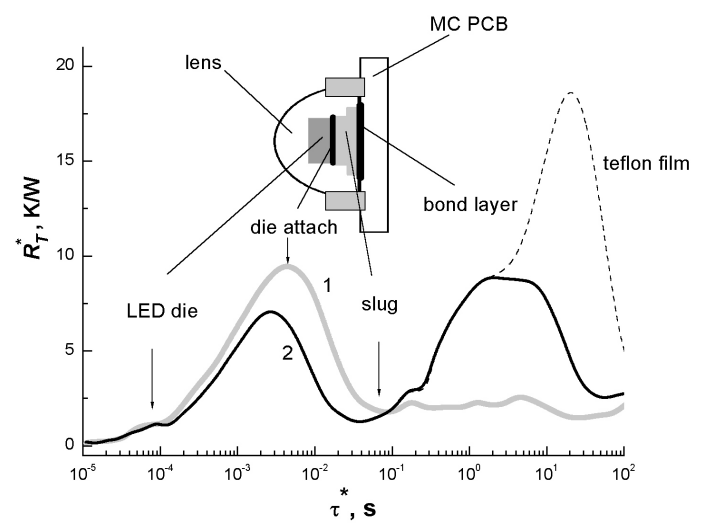

Fig. 7. Functions $R_{T}{ }^{*}\left(\tau^{*}\right)$ for two GaN LEDs (curve 1) LIIIP2JB and (2) LXK2.

\section{Conclusions}

Thus, the method of thermal characterization of heterolasers and LEDs based on transient measurements is discussed. The thermal resistances of the internal structure of heterolasers and LEDs as well as the optical power efficiency of heterolasers can be determined by the method.

A dominant contribution of the die attach layer to the internal thermal resistance of both heterolasers and LEDs is observed. For this reason, the method can be a useful tool for analysis and study of technological problems of die attach layer formation. In general, the interval of the specific values of the thermal resistance (per unit square) covers 2 to $20 \mathrm{~mm}^{2} \mathrm{~K} / \mathrm{W}$. The lowest values are characteristic for power QW heterostructure lasers in the AlGaInAs-AlGaAs system $\left(\approx 2 \mathrm{~mm}^{2} \mathrm{~K} / \mathrm{W}\right)$.

From the analysis of time behavior of heating temperature the current and temperature dependencies of laser output power efficiency were determined. The power efficiency of the investigated $\mathrm{AlGaInAs}-\mathrm{AlGaAs}$ heterolasers reaches up to $\approx 35-45 \%$ for pumping at $3 \mathrm{~A}$. In contrast, the power efficiency of the GaInAsSb-AlGaAsSb heterolasers reaches $\approx 10 \%$ for pumping at $80 \mathrm{~mA}$ as a result of their large series resistances.

\section{Acknowledgements}

The authors wish to thank A. Joullié, P. Christol, V.M. Lomako, V.V. Parashchuk, and S.S. Polikarpov for their help and fruitful discussions. Partial support of the work by the Belarusian Republican Foundation for Fundamental Research is also appreciated.

\section{References}

[1] V.P. Gribkovskii: "Injection lasers". Prog. Quantum Electron., vol. 19, no. 1, 1995, pp. 41-88.

[2] L.A. Coldren, S.W. Corzine: Diode Lasers and Photonic Integrated Circuits. John Wiley, N.Y., 1995.

[3] B. Mrozievich, M. Bugajski, W. Nakwaski: Physics of Semiconductor Lasers. North Holland, Amsterdam, 1991.

[4] J. Fitzpatrick: "Laser diode arrays: pump up the power". Photonics Spectra, vol. 29, no. 11, 1995, pp. 105108.

[5] R.V. Steele: "Diode doldrums". Laser Focus World, vol. 42, no. 2, 2006, pp. 69-78. 
[6] A. Joullié, P. Christol: “GaSb-based mid-infrared 2-5 $\mu \mathrm{m}$ laser diodes”. C. R. Physique, vol. 4, no. 6, 2003, pp. 621-637.

[7] A. Vicet, D.A. Yarekha, A. Pérona, Y. Rouillard, S. Gaillard, A.N. Baranov: "Trace gas detection with antimonide-based quantum-well diode lasers". Spectrochimica Acta. Part A, vol. 58, no. 11, 2002, pp. 2405-2412.

[8] I.V. Glukhikh, A.V. Matveentsev, S.S. Polikarpov, S.B. Sevastianov, A.P. Mayorov, A.D. Dub, V.G. Volkov, E.V. Gratsa: "0.81 $\mu \mathrm{m}$ CW laser bars with hyperthin InGaAs active layers". Technical Program, XI Conf. on Laser Optics, June 30-July 4, 2003, St. Petersburg, p. 61.

[9] K.A. Bulashevich, V.F. Mymrin, S.Yu. Karpov, D.M. Demidov, A.L. Ter-Martirosyan: "Effect of freecarrier absorption on performance of $808 \mathrm{~nm}$ AlGaAs-based high-power laser diodes". Semicond. Sci. Technol., vol. 22, no. 5, 2007, pp. 502-510.

[10] J.J. Hughes, D.B. Gilbert, F.Z. Hawrylo: "Measurement of the thermal resistance of packaged laser diodes". RCA Rev., vol. 46, no. 2, 1985, pp. 200-213.

[11] G.I. Ryabtsev, A.N. Kuzmin, J.A. Ges, Yu.P. Gorban, M. Soukieh, V.P. Konyaev, W. Stręk: “Thermal properties of high-power InGaAs/AlGaAs laser diodes”. J. Appl. Spectrosc., vol. 62, no. 5, 1995, pp. 900902.

[12] Yu.A. Bumai, A.S. Vaskou, D.S. Domanevskii: "Thermal processes in high-intensity InGaN/GaN lightemitting diodes”. Book of papers, $6^{\text {th }}$ Belarussian-Russian Workshop „Semiconductor Lasers and Systems", June 4-8, 2007, Minsk, pp. 108-112.

[13] J. Hulett, C. Kelly: "Measuring LED junction temperature”. Photonics Spectra, vol. 42, no. 7, 2008, pp. 7375.

[14] J.W. Sofia: "Analysis of thermal transient data with synthesized dynamic models for semiconductor devices". IEEE Trans. Components, Packaging, and Manufacturing Technol. Part A, vol. 18, no. 1, 1995, pp. 39-47.

[15] V. Székely: “THERMODEL: a tool for compact dynamic thermal model generation". Microelectron. J., vol. 29, no. 4-5, 1998, pp. 257-267.

[16] Y.C. Gerstenmaier, G. Wachutka: "Rigorous model and network for transient thermal problems". Microelectron. J., vol. 33, no. 9, 2002, pp. 719-725.

[17] G. Farkas, Q.van V. Vader, A. Poppe, G. Bodnár: "Thermal investigation of high power optical devices by transient testing". IEEE Trans. Components and Packaging Technol., vol. 28, no. 1, 2005, pp. 45-50. 